\title{
How children can be respected as 'ends' yet still be used as subjects in non-therapeutic research
}

\author{
Robert B Redmon Virginia Commonwealth University, USA
}

\section{Author's abstract}

The question of whether or not children may be used as subjects in non-therapeutic research projects has generated a great deal of debate and received answers varying from 'no, never' to 'yes, if societal interests are served'. It has been claimed that a Kantian, deontological ethics would necessarily rule out such research, since valid consent would be impossible. The present paper gives a deontological argument for allowing children to be subjects in certain types of research.

Is it morally permissible to use children as subjects in non-therapeutic research?

Before attempting to answer this question and commenting on what some others have said about it, I need to define my terms somewhat. By 'children' I mean individuals below the 'age of reason', that is, those individuals whom we think, by reason of their lack of years, are unable to make rational decisions on those matters which affect their long or short-term interests, or who are unable, because of age, to make rational moral choices in a great many areas. I do not intend to suggest when this occurs, although with most children it probably occurs before the legal 'age of consent', which is generally eighteen. It is true, however, that the word 'consent' must be followed by 'to -' to be meaningful. Thus we certainly allow children to consent to some things while not others, and if we preface 'consent' by 'informed' it is even clearer that different children at different ages can be adequately 'informed' of risks, benefits, and purposes of different medical procedures, including experimental ones. It is also true that 'child' is not simply a biological term $(1,2)$. A child is someone who 'plays the child role' (to use Englehardt's phrase), and that role varies from culture to culture. The clear case of a child in non-therapeutic research would be that of an infant involved in, say, certain studies on metabolism.

By 'non-therapeutic research' I mean medical intervention directed towards the child which is

\section{Key words}

Ethics, medical; human experimentation, children; research, paediatric. intended more for the purpose of producing knowledge, than for the benefit of the child, and which would be done even if there were no benefit to the child. For example, we may suppose that the earliest experimental trials with the Salk polio vaccine were more likely to injure the children involved, than prevent harm by protecting them against polio. Nontherapeutic research could also include any extra tests of a hospitalised patient to try to understand why he was improving (the patient may not care why, as long as his condition does improve) and certain aspects of randomised clinical trials. Note that determining the physician/researcher's intent may be crucial in classifying research as non-therapeutic (3). ('Experiment' or 'research' will mean non-therapeutic experiment' or 'non-therapeutic research in what follows.)

I don't mean to suggest that it is always clear that a particular experiment falls on one side or the other of the therapeutic/non-therapeutic dichotomy, but the concern of the present paper is with research that does. Also, this definition of 'non-therapeutic' does not correspond with some characterisations of the distinction, focusing, as it does, upon intent, rather than results. However, for purposes of moral analysis, it seems superior to a criterion which would only inform the researcher or others that they have been involved in non-therapeutic research after the fact.

\section{Ethical theories}

The two ethical theories which presently dominate Western philosophical thought, and indeed seem to appear in some form in almost every moral dispute, are those which have been best articulated by Immanuel Kant (4) and John Stuart Mill (5). Each outlook emphasises certain aspects of our moral life, and instructs us to view human action in a certain way. Like competing scientific theories, they do not simply supply us with different answers to the same questions,

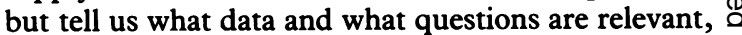
and which are not. The simple view that scientific theories replace each other because the data dictate a certain answer is mistaken, as such writers as Kuhn (6) and Hansen (7) have shown us. Likewise, the Kantian and utilitarian (that of Mill) views do not simply give 
different answers to the same question, 'What is right?', but the concepts of 'right,' 'obligation,' etc, seem to be different in each theory. Also, as with scientific theories, although the data do not dictate the theory, they certainly constrain and limit possible answers. One cannot simply flip a coin to pick either a scientific or a moral theory. The fact that, 'one can believe what one wishes' in ethics is true of factual matters as well ('my mind is made up, don't confuse me with the facts'). Much depends upon one's desires for consistency and coherence.

Before we drown in the depths of moral philosophy, however, I wish simply to characterise what I take to be the relevant concepts of these two theories, and how they might tell us to view the question at hand concerning human experimentation and children.

The Kantian view, or the relevant aspect of it for us, is seen in Kant's second formulation of the Categorical Imperative:

'Act so as to treat humanity, whether in your own person, or in that of another, always as an end and never as a means only' (4).

In other words, do not (merely) use people. The concepts which are important in the Kantian view are 'motive', 'duty', 'obligation', and 'respect for persons'. The fact that moral duty plays such a central role in Kant's philosophy has caused writers to characterise his view as 'deontological' (from the Greek word deon which means 'duty'). However, many popular writers distort this concept of duty to mean a sometimes silly type of absolutism (aided no doubt by Kant's own examples). It is not difficult to undermine a view which says 'Do not do $\mathrm{x}$ whatever the consequences' for almost any ' $x$ ' you could think of. (Never lie? Never hurt someone? Never kill? whatever the consequences of obeying the rule?)

The concept of obligation is also central to Kant. If I break a promise to another, I not only use him (to obtain something for myself), but I break an obligation. A Kantian ethic of medical practice would focus upon those duties and obligations which are incurred by the physician because of his particular station, because of his humanity, and because of the particular promises, either explicit or implicit, he has made to his patient.

A second Kantian notion, that of 'respect for persons' or treating them as 'ends', needs to be developed, and I will do so, to a certain extent, later. But suffice it to say that treating someone as an 'end' does not mean simply doing what is best for her. Rather it means, in part, to take her goals and desires as important, to see her values as valuable, in other words, to respect her as a person. The phrase 'respect for persons' is often used to characterise this aspect of Kant's thought.

The utilitarian view, that of Mill, is somewhat simpler. As Mill stated it:

'Actions are right in proportion as they tend to promote happiness; wrong as they tend to produce the reverse of happiness. By happiness is intended pleasure and the absence of pain ...' (5).

Notice that, on this view, motive has nothing to do with the rightness of an act, though, as Mill claimed, it does have something to do with the moral character of the agent. It is the consequences which matter. In our ordinary way of speaking we often say that we see now that we did the wrong thing, although, at the time it seemed the right thing to do, and the motives were, and are, good. What makes us come to see that it was not the right thing to do are the now-realised consequences. (One might wonder if the word 'right' is used in the same way as Kant would use it.)

\section{Human experimentation}

The moral issues surrounding human experimentation have generated a veritable library of law and moral reasoning, beginning in our time with the disclosure of the Nazi atrocities. The problems of research on prisoners, the mentally incompetent, research involving deception (for example psychological experimentation, experiments with placebos), the question of informed consent, the supposed moral advantage of retrospective studies over clinical trials, have all given rise to a massive literature which indicates the complexity of the moral problems of human experimentation.

One complication is that on the surface there seems an obvious conflict between what the Kantian and the utilitarian would say about human experimentation. It seems apparent that the experimental subject is being used for some greater goal. The utilitarian might well argue that if the consequences for people as a whole including the untold thousands who might be benefited or even saved by a drug - is great enough, then it justifies the risks to a few. The Kantian might reply that it is wrong to merely use people, regardless of the benefits to others.

As Hans Jonas points out in his excellent paper (8), human experimentation is a particularly difficult problem for the Kantian. What I shall attempt in this paper is a Kantian justification for research with children as subjects. That is, I shall argue that there are some conditions under which, on Kantian grounds, such research is acceptable.

Of course, the utilitarian side of the issue is not quite as straightforward as I made it out to be in the beginning of this section. The effects of deliberate mistreatment of dependent persons, whether children, the sick or mental incompetents, are more than just the harm to those individuals. It may poiscn our whole moral fabric and distort our moral sensibilities, which are certainly effects to be considered in the utilitarian calculus. However, the utilitarian could justify the use of children in research provided there was a real prospect of sufficient benefit to others as a result.

It is interesting that the moral conflict we see in this problem can even be viewed as a conflict between two 
Kantian-type duties, rather than simply a utilitarian $v$ a Kantian one. Robert Marston, quoting Dr George James with approval, wrote:

'In the discussion of ethical considerations relating to clinical research, Dr James said, "the right of the unborn generations to benefit from the fruits of research must also be weighed. It can be debated that no man today has the free and moral right to condemn his grandchildren to the same perils of disease to which he is exposed, by virtue of the present lack of effective scientific information, and his failure to participate in a search for it. .." '(9).

This apparent conflict of duties - one to society at large, one to the patient - is argued to be nonexistent by Jonas. The physician obviously has a duty to his patient. It is an obligation which results from a promise made to the patient. The 'duty' of the researcher is less clear. Do doctors and scientists owe society a cure from disease? Does society have a right to such success from the researcher? If a cure is found it appears to be more of a gift, like a matter of grace, than the fulfilment of a right. It indeed seems odd for James to refer to the researcher, government, or society as 'condemning' people to their diseases. Did previous generations condemn their children to polio? In any case, the duty of a researcher to society is not as clear as that of the physician to his patient.

The distinction between the physician/patient relationship and the researcher/subject one is alluded to in the World Medical Association (WMA) Declaration of Helsinki (10) and was brought out forcefully in the famous case of the experiments in the Jewish Chronic Disease Hospital in Brooklyn which were disclosed in 1964 (11). In this study live cancer cells were injected into patients, many of whom were debilitated, elderly, and suffering from decreased mental ability. The patients were never told that the material used consisted of live cancer cells. The justification for not telling was that the word 'cancer' would 'unduly alarm' the patients, and that there was little risk in the experiment. The New York Board of Regents rejected this argument with the following:

'No consent is valid unless it is made by a person with legal and mental capacity to make it, and is based on a disclosure of all material facts. Any fact which might influence the giving or withholding of consent is material. . .

'It is not uncommon for a doctor to refrain from telling his patient that he had cancer where the physician in his professional judgment concludes that such disclosure would be harmful to the patient. . . The researchers overlooked the key fact that so far as this particular experiment was concerned, there was not the usual doctor/patient relationship, and therefore, no basis for the exercise of their usual professional judgement applicable to patient care' (11).
The physician has some latitude (how much is a matter of great debate) in informing his patient of the risks and other factors in a therapeutic procedure. The researcher has none. One reason is that the physician is working on behalf of his patient and the researcher need not be.

Thus, the type of paternalistic behaviour we might allow in the physician is not permissible in the researcher. In the same way, the usual justification we give for substituting the parents' consent for the child's in medically treating children is not valid in the case of non-therapeutic research.

\section{A Kantian solution}

If we are to treat persons as ends, how is experimenting with them justifiable? One way that it might be seen as morally acceptable is to take the path that Jonas does. If the goals of the subject are the same as the researcher, then the subject is not being merely used. The researcher is furthering the subject's goals by allowing him to be part of the research. A necessary condition for such 'identification' (as Jonas calls it) with the project is that the subject be fully informed, not only as to risks, but also as to the purposes of the research. The (morally) best subjects would thus be researchers themselves who can best appreciate the research project. The most unacceptable subjects would be the sick, and finally the children and the mentally ill who cannot possibly understand the research, and who cannot be said to have consented rationally. The sick, who are often used in this way, are unacceptable as subjects since they are too vulnerable to intimidation by their doctors. They must be protected - not used The only possible exception would be for (non-therapeutic) experimentation related to their own disease. One might very well say to himself that although this disease was killing him, he would try to prevent it from killing others by being a research subject. This Kantian solution, and restrictions, seem to rule out children altogether.

\section{Children as research subjects}

If we assume that medicine as a whole, or paediatric medicine in particular, is a good, (12) it becomes clear, I think, that minimal risk, non-therapeutic research with children is needed in a great many areas of paediatrics. From my own limited experience I know that the life-saving monitoring and regulating of blood gases in many distressed newborns could only be accomplished by knowing what the normal levels are, ie, by taking blood samples from normal infants. There are numerous examples like this, and they strike even the layman who visits a paediatric ward in a modern hospital. However, we generally hold it as a moral principle that parents or guardians can only consent for those things which are to the benefit of their children. Thus we will not allow a parent to withhold a lifesaving treatment from her child (when it is not in the child's best interest), or to permit her child to stay out of school. Citing such a principle, and a principle of 
informed consent, Paul Ramsey says:

'From consent as canon of loyalty in medical practice it follows that children, who cannot give mature and informed consent . . . should not be made subject of medical (non-therapeutic) experimentation ... and where there is no possible relation to the child's recovery, a child is not to be made a "mere object in medical experiementation" '(13).

Richard McCormick $(14,15)$ attempts to answer Ramsey by claiming that 'the good' of such children can be furthered by such experimentation. He claims that if they were capable of consent to non-therapeutic research they would consent (a type of hypothetical or implied consent) because they 'ought to do so' (16). Doing what one ought to do furthers his 'end', in some 'natural law' sense. W G Bartholome (17) gives several objections to such a claim as have many other writers, including Ramsey. My own objection is that McCormick assumes an Aristotelian 'end' or goal for human beings, which implies a type of 'function' for all of us. It is extremely doubtful, to me at least, that all persons have a function or purpose in this world, especially a moral one. And even if we did, forcing or manipulating others to do good hardly seems a way to further their moral ends. Also, as has been pointed out by others, such a view would allow us to force anyone to do what he ought to do, which seems an undesirable consequence. At the very least, it would make a shambles of our ordinary concepts of beneficence, charity, etc - of the distinction between what we ought to do because it is good to do it (for example charity) and what others have a right to and a claim on us for (for example, the keeping of promises, the repayment of debts). It would also allow an extreme paternalism, since what I 'ought to do' includes, for McCormick, what is in my (non-moral) best interest.

Secondly, if we construe our obligations to be subjects of medical research not as a duty of charity, but as an incurred debt of some sort (as McCormick (15) does in some writings), we still face difficult problems. Conscripting children to support a system about which they have no voice seems a very odd way to further their moral 'ends'. As the National Commission for the Protection of Human Subjects remarked: 'If the natural law justification is correct, it actually undermines the consent model by rendering it gratuitious' (17). (There is obviously another problem with conscripting anyone to be part of medical research - the fact that others, such as pharmaceutical companies, may profit from it. Such conscription would resemble being drafted into a private army.)

The first step towards understanding this prohibition against using children as experimental subjects is to understand why we deny children their freedom of action to begin with; why we think that paternalism (if that is too sexist a word, substitute 'parentism') is justified in regards to them, but not with adult rational persons. We cannot simply say that children do not know their best interests, and that is reason enough, because many adults a great deal of the time - and all of us some of the time-do not know what is in our best interests. Such a justification would allow us to prohibit any action we deem foolish, and would allow extreme paternalism towards everyone, children and adults alike. A better reason is that such restrictions on a child's freedom guarantee his autonomy in either or both of two ways: these restrictions protect the child from harm that would limit his freedom in the future (being seriously injured, or a lack of education), or these restrictions are what we think the child will later agree to, what he will later see as something he would do in his own interest. We assume a type of hypothetical consent, much the same way we do for the comatose emergency patient. (Note that 'implied' consent in that case is a misnomer - the unconscious patient has done nothing specific to imply a particular course of treatment.) We can justify our treatment of the comatose patient on the grounds that if he were awake, and rational, it is reasonable to assume that he would agree to the treatment (the socalled 'reasonable person' doctrine). Likewise, I can assume that when my child is older, she will be glad that I did not allow her to play in a busy street. Or if she is not, she is still freer than she would be if she had been run over by a truck.

Thus, one question is: under what circumstances, if any, can I expect my child to be pleased, to 'agree retroactively' when she is an adult, that I should have permitted her to be part of non-therapeutic research in which she was a subject? (Not 'when ought she to be pleased.') If there were some risk, and the possible benefits to society were small, we could not expect such agreement. For notice that we must add to the child's knowledge the fact that $\mathrm{I}$, as her parent, allowed her to be used this way. The child's own assent (18) (if she is over the age of four or five) must be a necessary condition for participation in such research; for it seems probable that the knowledge that she was used by her parents against her will would be too great a harm ever to allow her agreement with the decision to allow her to be part of the research project.

It seems reasonable to suppose that the (then) children involved in the first Salk vaccine trials may be proud now of their contributions, and agree with their parents in allowing them to be a part of the research. But lesser results and research may not have this effect. Can you imagine my daughter at age 21 saying 'I'm glad, Dad, that you allowed me to be part of the shampoo experiments, even though I might have become bald?'! My point is not that the actual results determine the morality of allowing children to be research subjects. Any risk for a new shampoo is too much. Some probability of some degree of harm is acceptable for the possibility of a great societal good. The Salk children's sense of contribution, together with their parents' and the researchers' belief that the overall risk/benefit ratio was highly favourable, would be necessary to justify the research.

There are other possible benefits (other than pride) to a child for being part of non-therapeutic research. If 
the child is old enough, she may enjoy seeing how this aspect of science functions, and her participation may aid her education. Also, this participation can be seen as part of her moral education. We certainly encourage our children to perform acts of benevolence when there is little chance of harm (walking down the road to take an invalid some food), and if the purposes of the research are understood well enough by the child, her participation might be viewed in the same way.

But if a child is an infant and too young to assent, much less consent, to such an experiment, then none of these benefits are possible. And, more importantly, what is required is a Kantian solution to this problem. Otherwise, the weighing of benefits can lead very easily to the misuse of the child.

However, these particular benefits - scientific and moral education - are of a different nature from most others (money, health, prestige, etc). To aid in the development of intellectual and, especially, moral abilities (or sensitivities) is to aid in the development of the individual's autonomy. For Kant, a person was only free when she was doing the morally praiseworthy thing (acting from 'a good will'). A development of a 'good will' (not withstanding Kant's view that such a will is 'non-empirical' and thus, in some sense, innate) is a step towards being an ultimate 'end'.

There is (to return to the 'future identification' notion), of course, a distinction to be made between what I can expect someone to 'agree' to, in this hypothetical, future sense, as part of their treatment for an illness, and what I can expect them to volunteer for. Part of what seems wrong with McCormick is the failure to distinguish between these two. The 'reasonable person' doctrine which allows us to treat the under-age, irrational or comatose patient without his will, is a defence or excuse concept. (If we have no information about the values or life-style of the comatose patient, how else can we determine what he or she would want except to ask ourselves what would a reasonable person agree to?) 'Reasonable' here, means 'reasonably self-interested'. It gives us no guidance, and, in fact, it makes no sense to ask what would the 'reasonable person' volunteer for. Are martyrs 'unreasonable'? Altruism, by definition, contrasts with concern for self-interest.

Thus in allowing such experiments with 'minimal risk' (no more risk than can be expected in the normal, protective environment of a child), we are wagering that the child will 'identify' and approve of such experiments. This 'hypothetical consent' cannot be judged on the 'reasonable person' hypothesis, since, as has been shown, it is difficult to predict how altruistic the 'reasonable person' would be in a moral situation. It does make sense, however, to ask how a person with a particular moral outlook, particular values, virtues and vices, would act. Thus the prediction of how the child will later view his participation must be made by those in the child's family, in particular by his parents. Their consent should be based upon their own values and the expectation that the child will share, to some extent, in them. They might reasonably expect for example, that their child may later, as an adult, have an interest in the welfare of children whom the research may benefit. Their child will probably be a parent himself. They should also, as the National Commission for the Protection of Human Subjects recommended (19), be present during all stages of the research, and be involved in it as much as possible. This will help confirm their judgement that their child will later 'identify' with the research project.

My 'Kantian deliberations' thus lead to a tentative conclusion: if we can reasonably expect this child to 'identify' (in Jonas's sense) with the goals of the research when she is an adult, and that the identification will be strong enough to outweigh the harm of the knowledge of being used by her parents, and if the child (if old enough) assents, and if the possibility of harm is slight ('minimal risk'), then such research is permissible. Anything less would break the convenant of which Ramsey speaks, to say nothing of what seems to be the closest thing we have to an ultimate moral principle - do not treat persons (and children are, or should be considered, 'persons') as objects, as merely a means to some other end. If this Kantian requirement is not met, then Ramsey is right: non-therapeutic research with children is morally indefensible (20).

Robert B Redmon, PhD, currently holds the Chair of the Department of Philosophy and Religious Studies at Virginia Commonwealth University (VCU) and is the Assistant to the Vice President for Ethics in Health on the Medical College of Virginia campus of VCU.

\section{References and notes}

(1) Englehardt T. The ontology of abortion. Ethics 1974; 217-234.

(2) Hauerwas S. Rights, duties, and experimentation on children: a critical response to Worsford and Bartholome. Appendix to report and recommendations: research involving children, The National Commission for the protection of Human Subjects of Biomedical and Behavioral Research. DHEW Publication, 1977: 432439.

(3) To see how crucial the question of intent may be, the o reader is referred to the debate which followed the $N$ disclosure of the research on hepatitis which was conducted at the Willowbrook State School in Staten Island, NY, in the 1960s in which children were intentionally exposed to the disease. For a brief account 0 of this debate, see Gorovitz S, ed. Moral problems in medicine. Englewood Cliffs: Prentice-Hall, 1976: 123150.

(4) Kant I. Foundations of the metaphysics of morals, originally published in 1785 . Translated by Lewis White Beck. New York: Bobbs-Merrill, 1959: 47.

(5) Mill J S. Utilitarianism, originally published in 1861. New York: Bobbs-Merrill, 1957: 10.

(6) Kuhn T. The structure of scientific revolutions. Chicago: University of Chicago Press, 1970.

(7) Hansen N. Patterns of discovery. Cambridge, UK: Cambridge Univerity Press, 1958. 
(8) Jonas H. Philosophical reflections on experimenting with human subjects. Daedalus 1969; Spring: 219-247.

(9) Marston R. Medical science, the clinical trial, and society. In: Beauchamp T, Walters L, eds. Contemporary issues in bioethics. Encino: Dickenson, 1978: 409.

(10) World Medical Association. Declaration of Helsinski 1964. Reprinted in Beecher H B. Research and the individual. Boston: Little-Brown, 1970: 270. In that document, experimentation with children was accepted if there was consent from a legal guardian.

(11) Langer E. Human experimentation: New York verdict affirms patient's rights. Science 1966; 151: 663-666.

(12) Some writers have argued that it is not. Ivan Illich's Medical nemesis, New York: Pantheon Books, 1976, provides a well-written, well-researched and thoughtprovoking support for this latter claim.

(13) Ramsey P. Consent as a canon of loyalty with special reference to children in medical investigation. In: Ramsey P. The patient as a person. New Haven: Yale University Press, 1970: 11-12.

(14) McCormick R. Sharing in sociality. Hastings Center report 1976; VI, 6: 41-46.

(15) McCormick R. Proxy consent in the experimental situation. Perspectives in biology and medicine 1974; 18, 1 : 2-20. Reprinted in: Mappes T A, Zembaty J S, eds. Biomedical ethics. New York: McGraw-Hill, 1981.
(16) See reference (15): Mappes T A, Zembaty J S, eds: 165

(17) Bartholome W G. The ethics of non-therapeutic clinical research on children. In National Commission for the Protection of Human Subjects of Biomedical Behavioral Research, Appendix: research involving children (1977). DHEW Publication No (05) 77-0005, 1977: 3.23-3.54.

(18) The National Commission (19) used the word 'assent' rather than 'consent' because the child may not fully comprehend the nature of the research, and is thus not consenting to it.

(19) The National Commission for the Protection of Human Subjects of Biomedical and Behavioral Research. Report and recommendations: research involving children, DHEW Publication No (05) 77-0004, 1977: 13.

(20) It should be noted that the National Commission's recommendations (and the subsequent regulations which follow it) correspond in large part with the proposals made here, in particular the minimal-risk requirement, and the requirement that parents be actively involved. However, the Commission's report appears to be the result of a rejection of any sort of consent requirement on the part of the children themselves, and is an argument from a utilitarian standpoint, with an undefined (granted, commendable) regard for children. 